\title{
A Training Program Based on Brain Gym to Develop Auditory and Visual Memory in English Language for Kindergarten Children Predictive of Learning Difficulties
}

Prof. Dr/ Aml Mohamed Hassona. *

Prof.Dr/Jehan Mahmoud El-Bassuony. **

Rania Salem Salama Salem. ***

\section{Abstract:}

The research aimed to measure the effectiveness a training program based on brain gym for developing auditory and visual memory in English language among kindergarten children predictive of learning difficulties in English language. Battery diagnostic measures for the difficulties of "social and emotional" behavior (Prepared by: Fathi El Zayat). The quasi-experimental approach was used by the one-group method, and the research tools included a pre- and post-auditory-visual memory scale (prepared by the researcher). The researcher used a training program based on brain gym to develop auditory / visual memory in English language among kindergarten children predictive of learning difficulties (prepared by

* Professor of Child Psychology (Ment: Head of the Psychological Science, Faculty of Early Childhood Education - Portsaid University.

** Professor of Curricula and Methods of Teaching English Language Faculty of Education - Port Said University.

*** Researcher, Department of Psychological Sciences - Faculty of Early Childhood Education - Portsaid University. 
the researcher) to be applied to a sample of (15) children, male and female, at the second level of kindergarten stage. The results of the research have proven the effectiveness of the training program based on brain gym in developing memory (audio - visual) in English language among kindergarten children who predictive of difficulties in learning English language.

\section{Research Terminology:}

- Training program.

-Brain gym.

- Auditory / visual memory.

- Kindergarten children predictive of difficulties in learning English language.

\section{Introduction:}

Learning disabilities is an important topic in the field of special education, and it has received a tremendous amount of attention from specialists and researchers. This may be due to the size of the problems and challenges that students face in different educational stages as a result of learning difficulties. This is in addition to the ambiguity of this concept and the difficulty of distinguishing it from other categories of special education and the categories that are similar with them, 
such as academic delay and slow learning. Most children who have learning difficulties had difficulties in learning reading, writing and mathematics, and they had impairment of long-term memory (retention and recall) in controlling concepts (Hammadena, 2017).

In this field, different strategies, styles, and methods have been developed to educate and train people with learning difficulties and to develop their abilities and skills. One of such methods is the brain gym developed by researchers Dennison \& Dennison in the mid-seventies of the twentieth century. It is based on early intervention with the aim of integrating body movements with the mind and learning through a series of exercises designed to help learners create coordination between their brains and bodies in an integrated manner. It also aims to Creating a balance between the left and right hemispheres of the brain, improving the flow of Dopamine and Norepinephrine, increasing blood flow to the prefrontal cortex, and improving memory and academic skills such as reading, writing, counting, mathematical skills, as well as social skills, such as social communication, forming relationships and social competence (Brain Gym International, 2011). 
In this regard, the study of Andrea (2012) aimed to verify the effectiveness of brain gym activities on the academic participation of children with learning difficulties, through research based on experimental evidence in the effect of brain gym movements on such children's behaviors necessary to complete the task. The results will help practitioners to accept or reject brain gym as an effective activity to improve children's academic behaviors, in the wake of the latest educational legislation, as there have been new educational methods applied in the school system. One of the methods that were implemented is the Educational Kinesiology Program based on a program called "Brain Gym". This study has shown some positive effects on the percentage of behaviors needed to complete the task with brain gym activities.

The results of a research study by Dorothea Paige (2003), Witzlar, Germany, conducted in a school district, concluded that children who did brain gym activities read faster, made fewer mistakes, and had a better understanding of the test material than the two comparison groups (Brain) Gym Journal, Aug. 2003). 
Patrick Le Maire (2002) pointed out that memory is a cognitive process through which learning and retrieval of what has been learned and gained from previous experiences is done. The first process takes place by receiving information to process it in working memory and then storing it in long-term memory. The second process is retrieval and extraction of information stored in long-term memory to short-term memory to use it (Elsayed \& Rakza, 2020, 81).

The researcher believes that memory (auditory - visual) is one of the important skills that must be studied as one of the psycho-linguistic skills, as the weakness of memory or the decrease in the ability to retrieve information is one of the deficiencies of the child predictive of difficulty in learning. It is worth noting that this difficulty does not appear in the child's ability to remember things that happened a long time ago, i.e. longterm memory, but the problem lies in the weakness of short-term memory.

The use of brain gym for children predictive of learning difficulties to develop auditory and visual memory in English language may result in an improvement in the level of their visual and auditory memory, especially if 
this use is done in a systematic and effective method in an organized program, which is what the current research tries to look in and consider.

\section{The Research Problem:}

Based on the researcher's experience with the reality of kindergartens during her work as a kindergarten teacher and direct contact with children, and based on the importance of English language as one of the necessary requirements for children's adaptation to modern progress in education, and in light of some previous Arabic literature that emphasized the effectiveness of early intervention to develop the child's auditory and visual memory and the extent of the effectiveness of the programs presented to improve these capabilities, the researcher could emphasize the importance of auditory and visual memory for kindergarten children in general, and those who are predictive of learning difficulties in particular.

The researcher sought to study the strength and weakness points of the cognitive channels of kindergarten children who are predictive of difficulties in learning English language, with the aim of diagnosing those points 
and seeking to improve and develop weaknesses by developing and designing a program to treat deficiencies in the auditory and visual memory of children (the research sample).

This was done through open interviews with some kindergarten teachers and mothers of children. The interviews were conducted with the aim of getting acquainted with the views of the teacher and the mother on the cognitive abilities that the child lacks and that limits creativity among children predictive of learning difficulties while interacting with the teacher and peers. Through these interviews, it was revealed that the child's level of auditory and visual memory in English language has been low. In addition, open interviews were held with some of the children predictive of learning difficulties to determine the visual and auditory abilities which they lack and which affect memory in learning English language.

In view of the foregoing, and with the researcher's observation that there are no local studies and research that have dealt with this topic, as this area lacked previous studies and research, and with the importance of developing treatment strategies that help reduce auditory 
and visual memory difficulties in English language among kindergarten children who are predictive of learning difficulties and improve their academic performance in English, it has been revealed that training programs based on brain gym may be effective in developing auditory and visual memory in English language in kindergarten children who are predictive of learning difficulties.

Therefore, the current research attempts to answer the following main question:

What is the effectiveness of a training program based on brain gym in developing auditory and visual memory skills in English language among kindergarten children who predictive of learning difficulties?

This main question is divided into the following sub-questions:

1)What are the training activities that can develop the memory (audio - visual) in English language for kindergarten children who predictive of learning difficulties? 
2)What are the differences between the scores of kindergarten children who are predictive of learning difficulties in the pre and post measurement of memory (auditory - visual) in English language?

3)What are the differences between the scores of kindergarten children who are predictive of learning difficulties in the post and follow-up measurement of memory (auditory - visual) in the English language?

\section{The Research Objective:}

In general, the research aimed to measure the effectiveness of a training program based on brain gym to develop memory (audio-visual) in English language in kindergarten children to reduce the difficulties of learning English language, in addition to knowing the extent to which the auditory and visual memory skills of children improved after applying the program later.

\section{Importance of the Research:}

- The importance of the current research comes through dealing with an important aspect of the educational process, which is to reveal the effectiveness of brain gym in developing auditory and visual memory in English 
language among kindergarten children who are predictive of learning difficulties.

- The results of this research may contribute to raising the level of cognitive awareness of kindergarten teachers and counselors about the benefit that might stem from brain gym in their interaction with children who are predictive of learning difficulties and improving the level of auditory and visual recollection skills in English language.

\section{Methodological Procedures of the Research:}

\section{First: The Research Sample:}

The current research sample consisted of (15) kindergarten children who predictive of difficulties in learning English language at the age of (5-6) years. The sample was intentionally chosen from the Kindergarten of Port-Said Official Language School in Port-Said Governorate, and homogeneity among the children of the study sample was taken into account by observing the following:

1- The chronological age of all children of the sample ranges between (5-6) years.

2- IQ scores should not be less than (90-110) on the Stanford-Binet Intelligence, the fifth edition. 
3- The children have obtained the highest score in the difficulty scale, prepared by (Fathi Mustafa Al-Zayat).

4- The children of the sample are those who are obligated to attend the kindergarten, as this facilitates their commitment to attend and hence, to the current study program.

5- None of children of the sample may suffer from obvious health problems or disabilities, so as not to affect their performance in the program.

Based on the previous conditions, the study sample was determined (15) boys and girls (9) males, and (6) females. Data were collected on the chronological age of the sample members from the lists of the school administration.

\section{Second: Research Methodology:}

The quasi-experimental approach, one-group design, was used to investigate the effectiveness of a training program based on brain gym for developing auditory and visual memory in kindergarten children predictive of learning difficulties. 


\section{Third: Research Instruments:}

The researcher prepared the following tools:

1.A scale of auditory and visual memory in English language for kindergarten children who predictive of learning difficulties (prepared by the researcher).

2.A program based on brain gym for developing auditory and visual memory among kindergarten children who are predictive of learning difficulties (prepared by the researcher).

3.A scale of auditory and visual memory in English language for kindergarten children who predictive of learning difficulties, the scale consists of two dimensions as follows:

\section{The first dimension: (Auditory memory):}

It refers to the ability of a kindergarten child to remember a series of auditory stimuli, and to arrange them and organize them in a sequence, such as arranging English letters or numbers.

\section{The second dimension: (Visual memory):}

It refers to the ability of a kindergarten child to remember a series of visual stimuli.

The scale was codified in terms of validity and reliability as follows: 


\section{Stability of the scale:}

The researcher used (Cronbach's Alpha Coefficient) to measure the reliability of the scale on a pilot sample consisting of (30), which was excluded from the main sample of the study. The following table shows the statistical procedure:

Table (1)

Demonstrates stability coefficients for the auditory and visual memory scale using Cronbach's alpha

\begin{tabular}{|l|l|}
\hline $\begin{array}{l}\text { Dimensions of } \\
\text { Psycholinguistic Skills }\end{array}$ & $\begin{array}{l}\text { Scale of Cronbach Alpha } \\
\text { Coefficient }\end{array}$ \\
\hline $\begin{array}{l}\text { The first dimension: auditory } \\
\text { memory }\end{array}$ & 0.911 \\
\hline $\begin{array}{l}\text { The second dimension: } \\
\text { visual memory }\end{array}$ & 0.980 \\
\hline Overall Score & 0.905 \\
\hline
\end{tabular}

From the previous table, It is evident that the general reliability coefficient for the scale dimensions is high, reaching $0.905 *$ for the total scale items. This indicates that the scale has a high degree of stability that can be relied upon in the field application of the research according to the Nunnalle Scale, which adopted 0.70 as 
the minimum stability.

\section{Validity of the scale:}

\section{Terminal comparisons validity:}

The scale was applied to the rationing sample $(\mathrm{N}=30)$ of kindergarten children who are predictive of learning difficulties and were not included in the final application of the scale in order to calculate the differences between the highest and lowest quartiles (27\%) of the children's scores, using the T-test shown in the following table:

\section{Table (2)}

Results of the T-test to study the differences between the averages of the peripheral groups of the auditory and visual memory scale of the pilot sample

\begin{tabular}{|l|l|l|l|l|l|l|l|l|}
\hline & \multicolumn{3}{|c|}{ Higher Quadrant } & \multicolumn{3}{c|}{ Lower Quadrant } & & \\
\cline { 2 - 7 } Variable & $\mathrm{N}$ & Mean & $\begin{array}{c}\text { Standard } \\
\text { Deviation }\end{array}$ & $\mathrm{N}$ & Mean & $\begin{array}{c}\text { Standard } \\
\text { Deviation }\end{array}$ & $\mathrm{T}$ & $\begin{array}{c}\text { Level of } \\
\text { significance }\end{array}$ \\
\hline $\begin{array}{l}\text { Auditory } \\
\text { visual } \\
\text { memory as } \\
\text { a whole }\end{array}$ & 8 & 8.750 & 0.462 & 8 & 5000 & 0.000 & 22.913 & 0000 \\
\hline
\end{tabular}

From the previous table, it is evident that there is a statistically significant difference at the level (0.001) 
between the highest and the lowest quartiles on the auditory and visual memory scale in favor of the mean of the highest quartile of the total sample. This indicates the differential validity of the auditory and visual memory scale, indicating that the scale has a high ability to distinguish between high and low memory. Thus, the researcher made sure that the auditory and visual memory scale has a high degree of stability on the pilot sample of the current research.

First: A program based on brain gym to develop auditory and visual memory in English language among kindergarten children who are predictive of learning difficulties.

The researcher designed and implemented a set of (30) training sessions based on brain gym, and the activities were formulated to cover all visual and auditory memory skills of the subject of the study. The activities were designed to develop such skills while properly employing kindergarten children who are predictive of learning difficulties. 


\section{The program build-up steps:}

The program was built with the following steps:

\section{(1) The general objective:}

The development of auditory and visual memory in English language among kindergarten children predictive of learning difficulties

\section{(2) Sub-goals:}

-Development of the child's ability of auditory recollection.

-Development of the child's ability visual recollection Procedural objectives.

\section{After completing the program, the child should be able to:}

-Retell three or more unrelated words as heard from the teacher, in the same order.

-Retell three sounds in the same order after hearing them from the teacher.

-Imitate the number of repeats of a sound up to three 
times.

-Retell five non-serial numbers after the teacher in the same order.

- Retell three sounds related to three pictures in front of them, and when each picture is displayed, the child speaks up the sound.

-Mention three actions a person took in three different places through a story that was presented to them.

-Mention four details in a picture that was shown to them for five seconds when asked verbally.

-Imitate four drawings, from memory, displayed for 10 seconds.

-Recall and remember things delayed after 5 seconds: Two stimuli are shown, then hidden and returned in a group.

-Point to things that have been seen before.

-Mention the names of four pictures of four people s/he remembers that were shown to them successively, a separate action for each person. 
-Execute commands and instructions presented to them acoustically.

Second: Building sessions and activities of the program based on brain gym:

In light of the goals that the program seeks to achieve, (30) training sessions have been determined aimed at developing auditory and visual memory to reduce learning difficulties in English language.

\section{Third: Preparing tools of evaluation :}

Three instruments of evaluation are used in the program:

1)Pre-evaluation: This is conducted before applying the program by applying the auditory and visual memory scale to the children of the experimental group, then recording the children's scores on the scale in order to determine the memory difficulties in their English language.

2)Formative evaluation: in which the child is evaluated continuously from the beginning of the program until its end. This is done on a daily basis during or after presenting the activity through cards presented to children 
daily as an application to the activity. It can be called (individual evaluation) to observe the progress made by children after undergoing the brain gym program and compare that to their scores before undergoing it.

3)Post evaluation: It is used after completing the application of the brain gym program to find out the progress achieved and compare that with the scores of children before undergoing the program. The auditory and visual memory scale is applied to children again.

\section{Research Hypotheses:}

Based on the research problem and objectives, the researcher determined the following hypotheses for the research:

1. There are statistically significant differences between the two means of the experimental group children's score ranks (the experimental study sample) on the auditory and visual memory scale in English language among kindergarten children who are predictive of learning difficulties before / after the application of the brain gym program in favor of the post-measurement.

2. There are no statistically significant differences between the two means of the experimental group 
children's score ranks (the experimental study sample) on the auditory and visual memory scale in English language among kindergarten children who are predictive of learning difficulties in the post and follow-up measurements.

\section{Research Findings:}

The hypotheses formulated were tested with the aim of ensuring the effectiveness of the brain gym strategy in developing psych-linguistics skills among gifted kindergarten children prone to learning difficulties in English language.

\section{Findings of the First Hypothesis: Discussion and Interpretation:}

The first hypothesis of the research states that:

"There are statistically significant differences between the two means of the experimental group children's score ranks (the experimental study sample) on the auditory and visual memory scale in English language among kindergarten children who are predictive of learning difficulties before / after the application of the brain gym program in favor of the post-measurement".

To verify the validity of this hypothesis, the researcher used the Wilcoxon Test for Correlated Groups to find the 
significance of the differences between the two means of score ranks of kindergarten children predictive of learning difficulties before applying the program and the two means of score ranks of the same group after applying the program, as shown in the following table:

\section{Table (3)}

The mean and sum of the negative and positive ranks and the $Z$ value between the pre and post measures on the psycholinguistic skills scale as a whole by Wilcoxon method

\begin{tabular}{|c|c|c|c|c|c|c|}
\hline Skills & \begin{tabular}{|} 
Rank of \\
the \\
Psycho- \\
Linguistic \\
Skills \\
Variable
\end{tabular} & \multirow[t]{2}{*}{$\begin{array}{l}\text { Number } \\
(\mathrm{N})\end{array}$} & \multicolumn{2}{|c|}{$\begin{array}{c}\text { Pre/post } \\
\text { Measurement }\end{array}$} & \multirow[t]{2}{*}{ Z Value } & \multirow[t]{2}{*}{$\begin{array}{l}\text { Statistical } \\
\text { Significance }\end{array}$} \\
\hline \multirow{5}{*}{$\begin{array}{l}\text { Auditory } \\
\text { / visual } \\
\text { memory }\end{array}$} & & & $\begin{array}{l}\text { Ranks } \\
\text { Mean }\end{array}$ & $\begin{array}{l}\text { Ranks } \\
\text { Total }\end{array}$ & & \\
\hline & $\begin{array}{c}\text { Negative } \\
\text { Ranks }\end{array}$ & 0.0 & 0.00 & 0.00 & \multirow[t]{4}{*}{-3.424} & \multirow[t]{4}{*}{0.001} \\
\hline & \begin{tabular}{|c|} 
Positive \\
Ranks
\end{tabular} & 15 & 8 & 120 & & \\
\hline & $\begin{array}{l}\text { Neutral } \\
\text { Ranks }\end{array}$ & 8 & & & & \\
\hline & \begin{tabular}{|c|} 
Total \\
Summation
\end{tabular} & 15 & & & & \\
\hline
\end{tabular}

According to the previous table, it becomes clear that there are statistically significant differences at the level of significance $(0.001)$ between the mean ranks of children who are predictive of learning difficulties in the study 
sample before and after the application of the program on the auditory and visual memory scale as a whole, used in the current study, in favor of the post application. The values of $\mathrm{Z}$ between the pre and post applications of the current study sample reached $(-3.424)$.

\section{Interpretation and discussion of the findings of the first hypothesis :}

It is evident, from the previous table, that there are statistically significant differences between the score ranks of the experimental group before and after applying the program on the auditory and visual memory scale in English language as a whole.

The findings of the research showed that there was an improvement in both auditory and visual memory of the members of the experimental sample after applying the training program to them. The improvement in visual memory is due to the program's containment of memory improvement strategies that are represented by (repetition - chuncking - mind maps).

During the application, the researcher has also taken into account the clarity of the presented visual stimuli, the arrangement of the presentation, the division of everything presented into categories, in addition to taking into account the number of the presented visual stimuli so that they do not exceed more than seven. The researcher 
also took into account the time of presentation of the stimuli so that it took less than 10 seconds. These stimuli contributed to increasing and improving the attention span of the children of the study sample, which contributed to improving visual memory.

As for the auditory memory, the findings showed a strong effect of the current program, as the program included training in auditory memory on a number of training tasks that helped improve this pattern of memory. The training program included two strategies to improve memory (repetition and coding), as well as the combination of new information and previous information for the child, which contributes to improving memory efficiency. Program activities in this component included renaming known solid models, recounting a group of words after being presented by the teacher, recounting sounds in the same order, and retelling a sentence.

The auditory memory training has taken into consideration improving the child's ability to make generalizations through the use of auditory memory to retain directions and instructions, improving the child's ability to follow related commands and instructions, retransmitting a verbal message to another person outside the classroom, and remembering a home address in detail including the street name and number, and the house 
number, in addition to retelling a phone number. Repetition is one of the important means of training in skills and emphasizing behaviors. The current research was not only limited to using this technique for instructions and explanation, but also extended to the use of the technique of repetition of activities.

The researcher attributes these differences also to the brain gym used in this research, where the auditory and visual memory deficiency in English language - which kindergarten children who are predictive of learning difficulties suffer from - is an important factor affecting memory deficiency in English language. Memory deficiency is reflected in the child's deficiency in both auditory and visual recollection, which in turn affects the ability of these children to satisfy their needs or desires to learn English language. It also reflects on the ability to recall and remember auditory and visual information. This affects the ability of these children to follow instructions and recall relevant information in English language. Hence, the preparation of the current program, including many objectives and activities based on brain gym, has become urgent. Consequently, the researcher sought to prepare the program in a way that suits the capabilities of children who are predictive of learning difficulties to achieve the objectives of the current research. The objectives of the program were applied to the members of the experimental group, which 
contributed to finding statistically significant differences between the mean scores of the experimental group children before and after the application of the program on audio and visual memory in favor of the post measurement.

The researcher believes that the choice of brain gym and the use of its techniques contributed to the development of auditory and visual memory among the children of the experimental group. Brain gym had an important role in increasing children's motivation to participate in the sessions and activities of the training program. In addition, brain gym affected the auditory and visual memory of these children "the experimental study sample."

\section{The findings of the second hypothesis: discussion and interpretation:}

The second hypothesis of the research states that "There are no statistically significant differences between the two means of the experimental group children's score ranks (the experimental study sample) on the auditory and visual memory scale in English language among kindergarten children who are predictive of learning difficulties in the post and follow-up measurements". 
To verify the validity of this hypothesis, the researcher used the Wilcoxon parametric test to detect the significance of the differences between the pre and follow-up measurements of the research sample. Table (4) illustrates the findings.

\section{Table (4)}

The mean and sum of the negative and positive ranks and the $Z$ value between the post and follow-up measures of the Wilcoxon Auditory Scale

\begin{tabular}{|c|c|c|c|c|c|c|}
\hline \multirow{6}{*}{$\begin{array}{l}\text { Scale of } \\
\text { auditory } \\
\text { and } \\
\text { visual } \\
\text { memory } \\
\text { as a } \\
\text { whole }\end{array}$} & \multirow{2}{*}{$\begin{array}{l}\text { Ranks of the } \\
\text { variable of the } \\
\text { auditory and } \\
\text { visual memory } \\
\text { scale }\end{array}$} & \multirow{2}{*}{\begin{tabular}{|l} 
Numbe \\
\\
N
\end{tabular}} & \multicolumn{2}{|c|}{$\begin{array}{l}\text { Follow-up \& } \\
\text { post } \\
\text { measurement }\end{array}$} & \multirow[t]{2}{*}{ Z-valu } & \multirow[t]{2}{*}{ Significance } \\
\hline & & & $\begin{array}{l}\text { Ranks } \\
\text { Mean }\end{array}$ & $\begin{array}{l}\text { Ranks } \\
\text { Total }\end{array}$ & & \\
\hline & Negative Ranks & 0.0 & 0.00 & 0.00 & 0.000 & 1.000 \\
\hline & Positive Ranks & 15 & & & & \\
\hline & Neutral Ranks & 0 & & & & \\
\hline & $\begin{array}{l}\text { Total } \\
\text { Summation }\end{array}$ & 15 & & & & \\
\hline
\end{tabular}


The previous table shows that there are no statistically significant differences between the two means of score ranks of children who are predictive of learning difficulties in the study sample after applying the program and after a month of post-measurement on the auditory and visual memory scale as a whole, which is used in the current research. The values of $\mathrm{Z}$ between the post and follow-up measurements of the study sample on the scale as a whole reached $(0.000)$.

\section{Interpretation of the second hypothesis findings:}

From the previous table, it is evident that there are statistically significant differences between the scores of the experimental group in the post and the follow-up measure on the auditory and visual memory scale as a whole. The researcher attributes these differences to the training program based on brain gym used in the current research. This is due to the continuing effect of brain gym on the research sample in the total score of the auditory and visual memory scale in the post and follow-up measurement.

The researcher believes that the use of brain gym has contributed to improving the child's motivation to accomplish the activities required of them. The diversity 
in the use of the audio and visual stimuli included in the training program led to the motivation of the child to pay attention to these stimuli more positively and to improve their performance in terms of memory.

During the implementation of the training program, the researcher took into account the transition of the effect of auditory/visual improvement during the child's reception of auditory and visual stimuli to improvement of reception and grasp of verbal instructions addressed to them. The child's ability to receive verbal vocabulary, which the researcher uttered during doing the training program activities, has increased.

The findings of the current research demonstrated the effectiveness of the program based on brain gym in developing auditory and visual memory in kindergarten children who are predictive of learning difficulties, as evidenced by the results of the two hypotheses. This reflects the tangible improvement in auditory and visual recollection that the auditory and visual memory scale measures after implementing the program. This indicates the utility of the program in developing auditory and visual memory. 
Thus, all the findings of the current research indicate that the two research hypotheses that the researcher tried to answer in the current research have been fulfilled. All of them aim to verify the effectiveness of brain gym in developing auditory and visual memory in kindergarten children who predictive of learning difficulties. The findings are evident through a comparison between the responses of the children of the experimental group in the pre- post and follow-up measurements.

These results confirm the effectiveness of using brain gym in developing auditory and visual memory in English language among kindergarten children who are predictive of learning difficulties. Based on the above, and by accepting the two research hypotheses, the training program based on brain gym has done well in developing auditory and visual memory in English language among kindergarten children who are predictive of learning difficulties.

\section{Recommendations and Proposals:}

Based on the foregoing, the researcher can mention the following recommendations and suggestions: 
1.Holding special courses for ordinary teachers who teach children who are predictive of learning difficulties in English language periodically to familiarize them with children with learning difficulties and how to deal with them.

2.Designing special programs for children predictive of learning difficulties who suffer from weakness and limitations in auditory and visual memory in English language.

3.Conducting more research and studies dealing with memory (especially successive auditory and visual memory) in English language for children who are predictive of learning difficulties in different environments other than the one in which this study was conducted in order to generalize the findings to a larger possible sample.

\section{Suggested Research:}

1. Conducting a study dealing with the effectiveness of brain gym in developing working memory in children predictive of learning difficulties.

2. Conducting a study that deals with the importance of brain gym in helping to teach English to children who are predictive of learning difficulties in the surrounding community. 
3. Conducting a study dealing with training kindergarten teachers to develop audiovisual memory for kindergarten children.

\section{Bibliography}

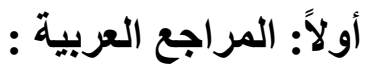

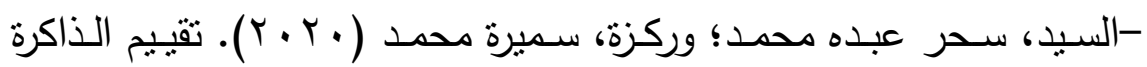

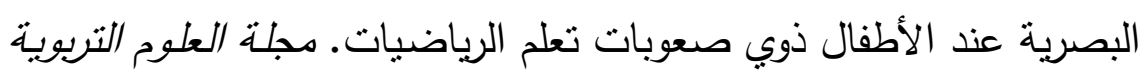

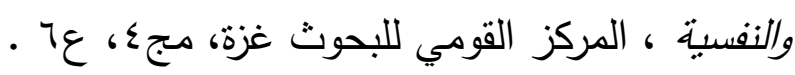

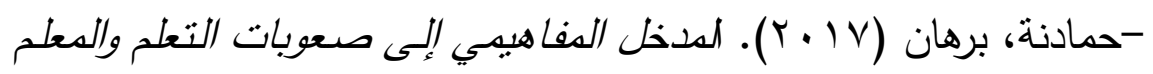
والأسرة. المملكة العربية السعودية: مكتبة الرشد.

\section{Second: Foreign Resources:}

-Andrea, Goodwin Watson, B.A (2012). The Effect of Brain Gym on On-Task Behavior for Children with Disabilities, Master of Arts in School Psychology, the Faculty of the Graduate School of Stephen F. Austin State University, IJMI Number: 1507360.

-Brain Gym International.(2011). Edu-K Style ide: The Style and Standards of Educational Kinesiology. Ventura، California, U.S.A.

-Brain Gym Journal, Aug.( 2003). Volume XVII, No. 2. 